\title{
Student Profiling and Key Dimensions- Enhancing Higher Education Learning and Teaching in Namibia
}

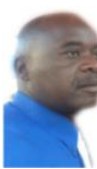

\& Corresponding Author

\author{
Dortea Shipena ${ }^{1}$ \\ Nchindo Mbukusa ${ }^{2}$ (6) \\ Timothy Sibanda ${ }^{3}$
}

\author{
${ }^{'}$ Namibian Police Force, Ministry of Home Affairs, Immigration, Safety and Security, Windhoek, \\ Namibia. \\ Email:ndootias@gmail.com Tel: +264813857620 \\ ${ }^{2}$ Higher Education and Lifelong Learning, University of Namibia, Windhoek, Namibia. \\ Email:nmbukusa@unam.na Tel:+264811298174 \\ ${ }^{3}$ Department of Biochemistry, Microbiology and Biotechnology, University of Namibia, Windhoek, \\ Namibia. \\ Email: tsibanda@unam.na Tel: +264612064970
}

The study reports findings that profiled students at the University of Namibia and discusses major dimensions enabling or hindering learning and teaching in higher education. The study further assesses the various teaching strategies preferred by students. Information ranging from gender, marital status, ethnicity, age, educational background and funding was analysed. To collect data, an online questionnaire survey link was distributed to 99 third year nursing students using their student emails. Simple random sampling method was quantitatively used to select 30 participants email addresses. About 21 students completed online survey questionnaires. Captured data was analysed descriptively through google documents to describe the study features. A five point Likert scale was used to measure participation, motivation, support, performance and inclusion, which remain crucial in enabling or hindering learning in higher education. Findings show that there was diversity in the classroom in terms of ethnicity, age, home languages. The student population dominantly comprised of northern tribes of Namibia. There were also students with disability, requiring special educational needs. The study revealed that students participated in the classroom through asking questions and get motivated by teacher feedback, and aspirations of having a brighter future. Students agreed that studying hard and attending classes will improve their academic performance, despite time and financial challenges. The study recommends that the university should re-assess student admission into programmes to ensure ethnic diversity. Further, the School of Nursing should hold career fairs to mobilise prospective students on the nursing career, especially with the aim to attract male candidates.

Keywords: Student profiling, Teaching, Learning, Higher education, Diversity, Participation, Motivation.

DOI: $10.55284 /$ ajce.v5i1.603

Citation | Dortea Shipena; Nchindo Mbukusa; Timothy Sibanda (2022). Student Profiling and Key Dimensions- Enhancing Higher Education Learning and Teaching in Namibia. American Journal of Creative Education, 5(1): 1-9.

Copyright: This work is licensed under a Creative Commons Attribution 3.0 License

Funding: This study received no specific financial support.

Competing Interests: The authors declare that they have no competing interests.

History: Received: 16 September 2021/ Revised: 13 January 2022/ Accepted: 26 January 2022/ Published: 11 February 2022

Publisher: Online Science Publishing 


\section{Highlights of this paper}

- Student profiling is a career-long procedure whereby students and their educators develop and maintain a documentary record of their teaching and learning experiences. Profiling helps students to steer their path through the options of modular degree courses.

- Higher Education is any of various types of education given in postsecondary institutions of learning and usually affording, at the end of a course of study, a named degree, diploma, or certificate of higher studies. Higher education also includes teacher-training schools, junior colleges, and institutes of technology.

- Teaching and Learning. Student learning in higher education is a function of both formal and informal experiences. Formal learning takes place as a result of a classroom or related activity structured by a teacher and/or others for the purpose of helping students to achieve specified cognitive, or other, objectives.

\section{INTRODUCTION}

Student profiling has only recently gained relevance in the academic domain. Higher educational transformation nowadays requires mutual participation by all stakeholders to inform practices or policies, including teaching and learning. Scholars in the field of education are devising strategies such as student profiling aimed at student-centricity in institutions of higher education to improve not only teaching and learning approaches, but also curriculum development and assessment. Barnett (2004) maintains that higher education across the world is undergoing a set of major changes. Some of these changes bring institutions of higher education into challenging relationships with the stakeholders in their wider environment such as the government, students as consumers, the world of work and, indeed, amidst competition and marketisation, other institutions of higher education. These major changes cannot be realised in higher education without understanding the consumers of the learning process - students. This conception is supported by Kreber (2002) as cited in Devlin and Samarawickrema (2010) who suggests that while teaching excellence entails sound knowledge of one's discipline, it also requires teachers to know how to motivate their students, how to convey concepts and how to help students overcome difficulties in their learning. We here hypothesise that excellence in higher education could be achieved through student profiling as well as availing of resources and student support.

\subsection{Student Profiling}

Ndlovu (2014) argues that student profiles describe the ways in which a student learns best based on information related to gender, culture and personality, needs and types of supports that have been successful in the past. This argument is buttressed by Kwembeya and Mbukusa (2019) who posit that student profiling is necessary for teachers to understand their students' learning styles before they could get ideas across and engage the students. Doing so will assists in developing the SNP which describes individual needs in four educational domains; participation, communication, personal care and movement (Northern Territory Government, 2015). As is increasingly becoming a trend in many higher education institutions (HEI), Namibian HEI need to employ the concept of profiling students as this could impact on quality education. Our study was inspired by a perception that teachers lack knowledge about their students, which information they need as it provides insights into students' learning needs and aspirations, and can better improve the learning management systems in higher education. Northern Territory Government (2015) posits that the Student Needs Profile (SNP) assists the process of identifying the specific needs of students who require adjustments to their learning programs and helps school staff meet their responsibilities.

\subsection{Motivation and Participation}

Cherry (2010) as cited in Nukpe (2012) views motivation as the process that initiates, guides and maintains goaloriented behaviours. Williams and Williams (2011) identifiy the five key ingredients impacting student motivation 
namely student, teacher, content, method/process, and environment. They also stated that the student must have access, ability and interest to learn, as well as valuing education. Equally, the teacher must be well trained, well focused and be able to monitor the educational process, be dedicated, inspirational and responsive to all students. The content must be accurate, timely, stimulating, and oriented to the student's current and future needs. The method or process must be inventive, encouraging, interesting, beneficial, and provide tools that can be applied to the student's real life. Lastly, the environment needs to be accessible, safe, positive and empowering as much as possible.

On the other hand, Gredler, Broussard and Garrison (2004) as cited in Lai (2011) state that motivation refers to "the attribute that moves us to do or not to do something." This can be done in two forms; intrinsic motivation which is motivation that is animated by personal enjoyment, interest, or pleasure. It is manifested in behaviors such as play, exploration, and challenge seeking that people often do for external rewards. Meanwhile extrinsic motivation is governed by reinforcement contingencies. According to Caruth (2018) there are five yardsticks for predicting student satisfaction and academic success, which are; the degree of course demands, depth of student-faculty relationships, level of inspirational scholastic experiences, quality of a helpful atmosphere, and intensity of a caring college environment.

\subsection{Student Support}

Wright (2011) states that students are the center of the educational enterprise, and their cognitive and affective learning experiences should guide all decisions as to what is done and how. The responsibility for learning naturally shifts to the student in a learner centered setting; neither students nor teachers are adept at making this shift. However, the onus is on the institutions of higher education to redesign and conduct the course in a way that requires students to hold up their end of the educational contract.

According to Kaur (2016) student support services (SSS) are a cluster of facilities and activities that are provided to make the learning process easier and more interesting for the learner. They serve as the interface between the institution and the learner. The quality of higher education depends directly on the student support services provided in various modes of higher education. If institutions of higher education are deficient in providing support to their students, then it does not serve the purpose of education, but only distribution of degrees. Students need support in all forms of education, formal or non-formal.

\subsection{Student Performance}

Simmons et al. (2005) cited in Shahzadi and Ahmad (2011) establish that family income level, attending full time, receiving grant aid and completing advanced level classes in high school as having statistically significant effects on college persistence among first generation college students. Adams (1996) as cited in Akessa and Dhufera (2015) and Rossi (2017) reveal that the most prevalent argument is that the socioeconomic status of learners affects the quality of their academic performance. Most of the experts argue that low socioeconomic status has negative effects on the academic performance of students because the basic needs of students remain unfulfilled and hence they do not perform better academically. An interesting variable affecting academic performance, which is not broadly analyzed, is working while in college. It translates to saying that students who are full-time employed have limited time to study and complete their academic tasks as opposed to full-time students. In addition, poor study habits, as observed by Shahzadi and Ahmad (2011) may adversely affect student performance. Students with poor study habits tend to obtain lower grades than those with better study habits. Hattie, et al. (1996) cited in Shahzadi and Ahmad (2011) point out that students' academic success in HEIs could be achieved when focusing on interventions directed towards learning strategies. Other than that, André (2014) states that the curricular performance of higher education students 
(HES) does not always meet expectations, of either the university, professors, or the student itself. This may be caused by a plethora of reasons including lack of planning and monitoring of the academic endeavor.

\subsection{Educational Inclusivity}

Braunsteiner and Mariano-Lapidus (2014) conceive inclusion to be the fundamental right of all children and adults to fully participate, and contribute in all aspects of the life and culture of an institution, without restriction or threat of marginalization. Braunsteiner and Mariano-Lapidus (2014) acknowledge Booth and Ainscow's work 'Index for Inclusion' which replaced the term special needs with that of barriers to learning and participation, creating a systematic approach where inclusion meets diversity. To promote inclusive cultures, structures, and practices requires the ability to increase learning and participation for all students and to emphasise these types of competencies in the educational experience of all candidates in teacher training programs (Booth \& Ainscow, 2002; Booth. \& Ainscow, 2011). Braunsteiner and Mariano-Lapidus (2014) state that despite a growing movement towards the model of educational inclusion, a number of vocal opponents including parents, teachers and educational scholars continue to resist the change. One assumption of resistance is that there is exceptionally narrow vision of inclusion, which leaves out other vulnerable groups and provides the opportunity to create reasons not to include children based on educational needs. Therefore, inclusion needs to be an umbrella of all challenges and hindrance to students' full participation as opposed to disability and marginalised needs.

On the other hand, Hardingrs (2017) posits that increasing opportunities for disabled students requires us to consider the social model of disability. This emphasises that disability is caused by the way society is organised, rather than by a person's impairment or difference and looks at ways of removing barriers that restrict life choices for disabled people. This further stresses that higher education providers could embrace and adopt this approach as it supports and guides the ways in which pedagogy; curricula and assessment were designed and delivered to engage students in learning that is meaningful, relevant and accessible to all.

King, Mitchell, McIntosh, and Bell-Ellwanger (2016) states that thousands of institutions define and pursue educational access and promote diversity in unique ways that relate to their educational mission and goals.

\section{RESEARCH METHODOLOGY}

A quantitative approach using 30 items on 5-point Likert-Scale $(1=$ strongly disagree, $2=$ disagree, $3=$ neutral, $4=$ agree and $5=$ strongly agree) to enable respondents rate on each characteristic was adopted. Items were designed to assess five dimensions associated to motivation, participation, support, performance and inclusion in higher education. Twenty-one (21) third year nursing sciences students at the University of Namibia Main Campus participated in the study following a simple random sampling procedure with equal probability of being selected (Neuman, 2015). The researcher drew a list of email addresses of the third year students from 1 to 99, and could only select 30 students.

\section{DATA INTERPRETATION AND DISCUSSION}

\subsection{Demographic Data}

The data collected was subjected to descriptive analysis using google docs. The analysis provided simple summary statistics about different variables. Of the 21 students who participated in the study, 89.5\% were female while $10.5 \%$ were male. Statistically, the findings show that there were significantly more female to male students in this nursing science student's cohort. All students were Namibian, and the Oshiwambo tribe was the most represented at $81 \%$, followed by Damara/Nama 9.5\%, and then Herero and Afrikaner, each at $4.75 \%$. Ninety-five 
percent $(95.2 \%)$ of the students were single while $4.8 \%$ were married. Students' home language varied from Damara, Afrikaans, KhoeKhoegowab, Otjiherero and Oshiwambo; the latter being the dominant language. Only $30 \%$ of the students resided in the hostel while $70 \%$ stayed outside campus, some as far as Rehoboth which is about $95 \mathrm{~km}$ South of Windhoek where the university campus is located. Ninety percent (90.5\%) of the students indicated not to have any known medical conditions. Similarly, $90.5 \%$ of the students no disability or impairment while $4.75 \%$ indicated that they have disability or impairment, mostly citing eyes problems, and $4.75 \%$ were unsure. This demography provided detailed information which enabled teachers to profile students and ensure provision of learning and teaching services tailored to student needs. Furthermore, this study found a good diversity in terms of ethnicity and languages, students' residence or accommodation, although gender representation remained a concerned as there are few male students than female. This data could be used to improve practices as well as enabling implementation of to the university policies to enhance the quality of higher education.

All students passed Grade 12 between the year 2015 and 2017, and they matriculated from diverse secondary schools both in towns and villages. Seventy-eight percent $(78.7 \%)$ of the participants only had a grade 12 certificate. Eighty-one percent ( $81 \%$ ) of the students indicated to have student loan, $9.5 \%$ self-funded their studies, and $4.7 \%$ got a scholarship, while $4.75 \%$ were funded by their parents. Differences were also noted in student's accommodation as some indicated that they stayed with their parents and relatives, some were renting, while some stayed in the university hostels. This information was vital for educators, as the possibility could be higher than those students funding their own studies or depending on their parents could face some various challenges which may affect their academic performance as opposed to their classmates who got loans and scholarships. Given the Covid-19 complications, the $70 \%$ nursing students staying outside the campus could be faced with challenges such as transport to and from school due to transportation restrictions, studying in isolation due to health regulations and not having sufficient food as some parents or guardian might have lost their jobs due to the economic crisis. Hence, their academic participation, performance and motivation may differ from those accommodated in the university hostels.

\subsection{Key Dimensions in Higher Education}

Tables 1-5 present 5-point Likert-Scale scores of the key factors of dimensions that affect student learning and performance in higher education.

Table 1. A 5-point Likert-Scale determination of factors affecting student motivation in higher education classroom.

\begin{tabular}{cllllll}
\hline & & $\mathbf{1}$ & $\mathbf{2}$ & $\mathbf{3}$ & $\mathbf{4}$ & $\mathbf{5}$ \\
\hline 1. & I can easily be motivated by other student's performance & 0 & 1 & 6 & 4 & 10 \\
\hline 2. & I am motivated by my teacher's feedback on my performance & 0 & 1 & 5 & 5 & 10 \\
\hline 3. & I enrol for the programme because my peers enrolled & 15 & 6 & 0 & 0 & 0 \\
\hline 4. & I think I can motivate myself because I want a brighter future & 0 & 0 & 3 & 3 & 15 \\
\hline 5. & I want to finish my studies in order to get a good job & 0 & 0 & 5 & 2 & 14 \\
\hline 6. & I want to attend the programme in order to obtain a qualification & 0 & 1 & 4 & 5 & 11 \\
\hline
\end{tabular}

Note: $1=$ Strongly disagree, $2=$ Disagree, $3=$ Neutral, $4=$ Agree $5=$ Strongly agree

\subsection{Motivation}

The findings revealed that students were highly motivated by other student's performance, teacher's feedback, aspirations of having a brighter future, better job and obtaining their degrees. The majority of students strongly disagree to having enrolled to the programme because of their peers, but rather their career desires. However, some students were neutral on how they get motivated. These findings concur with those of Caruth (2018) on yardsticks of student's motivation. 
Table 2. A 5-point Likert-Scale determination of factors affecting student participation in a higher education classroom.

\begin{tabular}{|c|c|c|c|c|c|c|}
\hline & & 1 & 2 & 3 & 4 & 5 \\
\hline 1. & I like asking questions regarding the subject & $\mathrm{O}$ & 3 & 5 & 5 & 8 \\
\hline 2. & I enjoy role plays and debates in class & 2 & 3 & 8 & 1 & 7 \\
\hline 3. & I prefer group discussions or activities & 2 & 2 & 7 & 5 & 5 \\
\hline 4. & I participate only when my teacher ask me a question & 6 & 7 & 4 & 3 & 1 \\
\hline 5. & I am too shy to participate in class & 7 & 6 & 4 & 2 & 2 \\
\hline 6. & I don't participate because other students are not participating & 13 & 7 & 1 & $\mathrm{O}$ & $\mathrm{O}$ \\
\hline
\end{tabular}

Note: $1=$ Strongly disagree, $2=$ Disagree, $3=$ Neutral, $4=$ Agree $5=$ Strongly agree

\subsection{Classroom Participation}

Most of the students indicated that they participated through asking questions. Minority of students (10\%) did not like role play and debate teaching strategies, others were unsure, but some enjoyed debating. Few students stated that they become shy to participate in class unless asked by the teacher and it seems students do not really enjoy group discussions or activities. This study revealed the same data as Williams and Williams (2011) advising that students must have access, ability, and interest, to value education. This will enable full participation and open engagement during classes.

Table 3. A 5-point Likert-Scale determination of factors affecting student support in a higher education setting.

\begin{tabular}{|c|c|c|c|c|c|c|}
\hline & & 1 & 2 & 3 & 4 & 5 \\
\hline 1. & I have all study materials needed for the programme & 3 & 8 & 5 & 1 & 4 \\
\hline 2. & I get the necessary support from my teachers & 1 & 5 & 9 & 2 & 4 \\
\hline 3. & My parents provide support at home & $\mathrm{O}$ & 2 & 3 & 7 & 7 \\
\hline 4. & I do have student financial assistance & 3 & 2 & 1 & 4 & 15 \\
\hline 5. & I only depend on my friends for my academic needs & 15 & 4 & 2 & 0 & $\mathrm{O}$ \\
\hline 6. & The dean of students is very helpful and addresses my problems as a student & 3 & 4 & 9 & 1 & 4 \\
\hline
\end{tabular}

Note: $1=$ Strongly disagree, $2=$ Disagree, $3=$ Neutral, $4=$ Agree $5=$ Strongly agree .

\subsection{Student Support}

These findings justified (Kaur, 2016) claims as students indicated various support methods. Students have however revealed not to have all study materials; some students disagree with getting support from teachers while others remained neutral about teacher support. Generally, all students indicated that they do not depend on their friends for their academic needs and this could mean that they either get support from their parents and teachers. The majority of students $(71 \%)$ indicated that they have financial assistance and this demonstrate that most nursing students have student loans from the Namibia Student Financial Assistance Fund.

Table 4. A 5-point Likert-Scale determination of factors affecting student performance in a higher education discipline.

\begin{tabular}{|c|c|c|c|c|c|c|}
\hline & & 1 & 2 & 3 & 4 & 5 \\
\hline 1. & I always try my best to pass well my assigned tasks/ tests/exams & O & $\mathrm{O}$ & 4 & 4 & 13 \\
\hline 2. & I do not understand when the teacher is teaching & 8 & 4 & 7 & O & 1 \\
\hline 3. & I always attend all my classes & 1 & 3 & 5 & 3 & 9 \\
\hline 4. & I have so many problems affecting my studies & 3 & 1 & 7 & 1 & 9 \\
\hline 5. & I do not have enough time to study & 3 & 8 & 7 & 3 & $\mathrm{O}$ \\
\hline 6. & Sometimes I feel like changing my course because it's difficult & 13 & 6 & 1 & 1 & $\mathrm{O}$ \\
\hline
\end{tabular}

Note: $1=$ Strongly disagree, $2=$ Disagree, $3=$ Neutral, $4=$ Agree $5=$ Strongly agree .

\subsection{Student's Performance}

Students strongly agreed to study hard and attend classes in order to obtain better grades; however, nine students agreed that they have so many problems affecting their studies and that they sometimes do not have enough time to 
study. These findings corroborate those of studies done by Shahzadi and Ahmad (2011); Rossi (2017) and Adams (1996) as cited in Akessa and Dhufera (2015) on student performance.

Table 5. A 5-point Likert-Scale determination of factors affecting student inclusivity in a higher education setting.

\begin{tabular}{|c|c|c|c|c|c|c|}
\hline & & 1 & 2 & 3 & 4 & 5 \\
\hline 1. & I believe that I am given equal opportunities like other students & $\mathrm{O}$ & $\mathrm{O}$ & 9 & 7 & 5 \\
\hline 2. & My admission into the programme was based on inclusivity & $\mathrm{O}$ & 2 & 9 & 5 & 5 \\
\hline 3. & The institution and teachers treats students according to their needs & 2 & 5 & 7 & 2 & 5 \\
\hline 4. & There is no electricity and internet at my house & 12 & 4 & 2 & $\mathrm{O}$ & 3 \\
\hline 5. & I feel like some students are given special attention than others & 4 & 6 & 5 & 4 & 2 \\
\hline 6. & Sometimes I do not attend classes due to a lack of taxi money & 8 & 3 & 6 & 1 & 3 \\
\hline
\end{tabular}

Note: $1=$ Strongly disagree, $2=$ Disagree, $3=$ Neutral, $4=$ Agree $5=$ Strongly agree .

\subsection{Inclusivity}

The majorities (43\%) of students were neutral about the status of their admission and equity issues. This could be attributed to the fact that student fear to express that they do not get equal treatment. $43 \%$ of the students have indicated unsure of whether the institution operates on equity policy. It seems $57 \%$ of the students live in houses with electricity and internet, while $14 \%$ seemed to have no access to electricity and internet facilities and this could negatively affect their studies, especial during crisis times, as is currently obtaining with the coronavirus pandemic which resulted in a shift from face-to-face instructional mode to online mode. Although majority of the students (43\%) were neutral regarding inclusivity practices at the University, the teachers still have to take cognisance of the minorities who indicated to have various needs and barriers hindering their effective learning as postulated by Booth and Ainscow (2002) advocating that for a systematic approach where inclusion meets diversity. This study has similar findings with that of King et al. (2016) regarding diversity, because these students were from various backgrounds, educationally, socially and economically.

\section{CONCLUSIONS AND RECOMMENDATIONS}

This study was pertinent as it explored ways of knowing students better, including their capabilities, weaknesses and needs. The study aimed at determining student academic backgrounds, and found that majority of the students only have Grade 12 certificate; however, there was a student with a master degree. Most of the students were single and very young by age, this could imply that the academic performance of single and young students could be good compared to the married and aging due to certain responsibilities. Hence, it became imperative for the teachers to understand these dynamics to be able to make reasonable adjustments for effective teaching and learning in Higher Education. Notably, there was ethnicity diversity; however, gender disparities appeared to be a major concern as there were more female students $89.5 \%$ compared to male $10.5 \%$. As such, this study makes a conclusion that male students avoid the nursing careers and there was a need to explore on the possible reasons. On the other hand, the Wambo seems to be the most aspired or admitted tribe into the nursing programmes. This could not only be attributed to the admission alone, but perhaps this admission was also based on application into the programme. This study further found that few students indicated to have disability or impairment; hence, consideration was required to provide special needs or rather break the barriers to full participation in learning for students who indicated to have difficulties or other challenges such as limited access to electricity and internet especially during this Covid-19 pandemic. It was good to note that students motivation was highly based on own aspirations of having a good job, brighter future and a qualification. Equally, many students indicated neutrality about the teaching strategies that could be most effective and inclusive. Funding for educations appears to be the prime hindering factor to student 
enrolment; nonetheless, it appears that most of the students do not have the necessary study materials such as internet devices, among others, while teachers' and parents' support remained moderate. The majority of the students had loans as means of funding for their studies, while some funded themselves while others depended on their parents for funding. Equally, students showed that they have many problems affecting their studies including inadequate time to complete their school work. Henceforward, the teachers and students should have mutual understandings and consultations to enable communication regarding matters affecting learning at HEIs.

\section{RECOMMENDATIONS}

The researchers recommend that this study be replicated to validate these findings. Higher education institutions should re-assess student admission into programmes to ensure ethnic diversity, as the study's participants was dominated by one tribe, which could possibly imply that some students from other tribes are not motivated enough to join the nursing field of study. Therefore, the school of nursing should hold career fairs to encourage students to take up the nursing career, and especially to attract male candidates. Importantly, a social model for disability needs to be incorporated in the learning and teaching policy in institutions of higher education to ensure equal opportunities to students in their societal and educational contexts. This approach supports and guides the ways in which pedagogy; curricula and assessment could be designed and delivered to engage students into meaningful learning, which is relevant and accessible to all. The university and the school of nursing should adopt a reasonable adjustment concept and practices. There is a need to review the university's policies s ensure that such policies may be written and managed in ways that do not preclude a smooth learning environment, taking into account of the relevant circumstances and consideration of a situation, thereby making reasonable adjustments to enhance inclusivity in education. As such, understanding of education inclusivity enables full participation and contribution in all aspects of life and culture, without restriction or threat of marginalisation and creates no barrier to learning. Lastly, further research could be conducted examining the barriers to participation in higher education as students indicated a lack of sufficient study materials and time to study as topical issues in higher education.

\section{REFERENCES}

Akessa, G. M., \& Dhufera, A. G. (2015). Factors that influences students academic performance: A case of Rift Valley University, Jimma, Ethiopia. Journal of Education and Practice, 6(22), 55-63.

André, D. M. P. (2014). Monitoring student's curricular performance in higher education. MSc Thesis in Information Systems and Computer Engineering: Tecnico Lisboa.

Barnett, R. (2004). The purposes of higher education and the changing face of academia. London Review of Education, 2(1), 61-73.

Booth, T., \& Ainscow, M. (2002). Index for inclusion: Developing learning and participation in schools. United Kingdom: Centre for Studies on Inclusive Education.

Booth., T., \& Ainscow, M. (2011). Index for inclusion: Developing learning and participation in schools. Bristol: Centre for Studies on Inclusive Education.

Braunsteiner, M., \& Mariano-Lapidus, S. (2014). A perspective on inclusion: Challenges for the future. Global Education Review, $1(1), 32-43$.

Caruth, G. D. (2018). Student engagement, retention, and motivation: Assessing academic success in today's college students. Participatory Educational Research, 5(1), 17-30.Available at: https://doi.org/10.17275/per.18.4.5.1.

Devlin, M., \& Samarawickrema, G. (2010). The criteria of effective teaching in a changing higher education context. Higher Education Research E̊ Development, 29(2), 111-124.Available at: https://doi.org/10.1080/07294360903244398.

Hardingrs, J. (2017). Inclusive teaching and learning in higher education as a route to excellence. UK: Department for Education. 
Kaur, S. (2016). Student support services in higher education: A student perspective. The International Journal of Indian Psychology, 3(9), 92349-93429.

King, J. B., Mitchell, T., McIntosh, A., \& Bell-Ellwanger, J. (2016). Advancing diversity and inclusion in higher education. Key highlights focusing on race and ethnicity and promising practices. U.S. Department of Education, Office of Planning, Evaluation and Policy Development and Office of the Under Secretary, Advancing Diversity and Inclusion in Higher Education, Washington, D.C.

Kwembeya, E. G., \& Mbukusa, N. (2019). Rethinking biology teaching at the University of Namibia: Insights from student profiling. The Namibia CPD Journal for Educators, 5, 326-353.Available at: https//doi.org/10.32642/ncpdje.v5i0.1247.

Lai, E. R. (2011). Motivation: A literature review research report. Retrieved from: http://images.pearsonassessments.com/images/tmrs/Motivation_Review_final.pdf.

Ndlovu, J. (2014). Developing learner profiles. Ministry of Education. Retrieved from https://www.inclusive.tki.org.nz/assets/inclusiveeducation/resources/files/Developing+Learner+Profiles+infosheet.pdf.

Neuman, W. L. (2015). Social research methods. Qualitative and quantitative approaches (7th ed.). India: Pearson.

Northern Territory Government. (2015). Student needs profile. A guide for schools, parents and carers. Department of education. Retrieved from https://education.nt.gov.au/_data/assets/pdf_file/0010/268831/student-needs-profile.pdf.

Nukpe, P. (2012). Motivation: Theory and use in higher education. Investigations in University Teaching and Learning, 8, 11-17.

Rossi, M. (2017). Factors affecting academic performance of university evening students. Journal of Education and Human Development, 6(2), 96-102.Available at: https://doi.org/10.15640/jehd.v6n1a10.

Shahzadi, E., \& Ahmad, Z. (2011). A study of academic performance of university students. Paper presented at the Conference Paper. Lahore, Pakistan.

Williams, K. C., \& Williams, C. C. (2011). Five key ingredients for improving student motivation. Research in Higher Education Journal, 12, 1-23.

Wright, G. B. (2011). Student-centered learning in higher education. International Journal of Teaching and Learning in Higher Education, 23(1), 92-97. 